\title{
Oxidative effects of glyphosate on the lipophobic intracellular environment in the microalgae Chlorella vulgaris
}

\author{
Juan Manuel OSTERA ${ }^{1,2}$; Susana PUNTARUlO ${ }^{1,2}$; Gabriela MALANGA ${ }^{1,2, *}$ \\ ${ }^{1}$ Fisicoquímica, Facultad de Farmacia y Bioquímica, Universidad de Buenos Aires, Buenos Aires, CP 1113, Argentina \\ 2 Instituto de Bioquímica y Medicina Molecular (IBIMOL), CONICET-Universidad de Buenos Aires, Buenos Aires, CP 1113, Argentina
}

Key words: 2', 7' dichlorofluorescein diacetate oxidation rate, Lipid soluble antioxidants, Round up, Redox balance

\begin{abstract}
The studied hypothesis is that the herbicide glyphosate (GLY) can affect the oxidative balance in the hydrophobic intracellular medium in non-target Chlorella vulgaris cells. Analytical GLY and RoundUp (RUP) supplementation, affected the growth profile. A significant $42 \%$ decrease in the cellular biomass in stationary (St) phase was observed in cultures supplemented with either $5 \mu \mathrm{M}$ of GLY or RUP, as compared to control cultures. The treatment with $0.3 \mu \mathrm{M}$ of GLY generated non-significant effects on the oxidation rate of 2', 7' dichlorofluorescein diacetate (DCFH-DA), neither in exponential (Exp) nor in St phase of development, as compared to control cultures. However, the treatment with either $5 \mu \mathrm{M}$ GLY or 0.3 and $5 \mu \mathrm{M}$ RUP lead to a significant decrease in the DCFH-DA oxidation rate, as compared to control cultures. The lipid radical $\left(\mathrm{LR}^{\bullet}\right)$ generation rate, detected by Paramagnetic Resonance Spectroscopy (EPR), was significantly increased in the presence of RUP, in Lag and Exp phase of growth. The non-enzymatic antioxidants, $\alpha$-Tocopherol $(\alpha-T)$ and $\beta$-Carotene $(\beta-C)$, are aimed to protect membranes against the damage produced by the radical reactions. The content of $\beta$-C was not significantly affected, as compared to control cultures, by any of the treatments, in both growth phases of cellular development. The content of $\alpha$-T was significantly decreased by the supplementation with either 0.3 or $5 \mu \mathrm{M}$ of RUP or $5 \mu \mathrm{M}$ GLY. The LR $/ \alpha-\mathrm{T}$ ratio, used as indicator of the oxidative balance in the hydrophobic cellular media, was significantly different between samples obtained from control and RUP-exposed microalgae in both, Exp and St phase of development, with either 0.3 or $5 \mu \mathrm{M}$ RUP. The data presented here showed evidence that suggested that oxidative balance in the hydrophobic environment was affected by either GLY or RUP.
\end{abstract}

\section{Introduction}

Glyphosate $\left(\mathrm{C}_{6} \mathrm{H}_{16} \mathrm{NO}_{5} \mathrm{PS}\right)$ (GLY) is a broad spectra herbicide that is mainly used for weed control in crops of agricultural interest. Studies over the past decade in a variety of biological models, have shown that GLY and its commercial formulations are responsible for associated toxicity of variable magnitude. GLY enters aquatic ecosystems by accidental spraying, drifts or surface runoff (Altamar Ríos, 2007). GLY generates the death of the target systems by affecting their ability to synthesize proteins essential for survival. The activity of the enzyme 5-enolpiruvilshikimato-3-phosphate synthase, which is part of the metabolic pathway for production of aromatic amino acids, is inhibited by the GLY that behaves as an analogue of the second substrate

*Address correspondence to: Gabriela Malanga, gmalanga@ffyb.uba.ar; gabriela.malanga@gmail.com

Received: 29 April 2021; Accepted: 15 June 2021 (phosphoenolpyruvate). Moreover, there is growing evidence that indicate that GLY (and its formulations) produce oxidative stress in cyanobacteria (Chen et al., 2012), microalgae (Lipok et al., 2010) and higher plants not natural targets for this herbicide (Ahsan et al., 2008). Also, it has been suggested that the pathological effects in humans are due to a mechanism of free radical production due to the nonspecific chronic inflammation that it generates (Altamar Ríos, 2007). In the air, GLY is eliminated through reactions with hydroxyl radical $\left({ }^{\bullet} \mathrm{OH}\right)$, and in the soil, it is degraded by the action of microorganisms, producing methylphosphonic ammonium acid (AMPA) and carbon dioxide $\left(\mathrm{CO}_{2}\right)$ (Altamar Ríos, 2007). In these reactions, free radicals and recombinant or fibrogenic cytokines are eliminated (Altamar Ríos, 2007). However, the real dimension of the magnitude of the oxidative effect generated by exposure to the herbicide is still a matter of deliberation.

The exposure of cultures of the algae Chlorella kessleri, to GLY at concentrations of $50 \mathrm{mg} \mathrm{l}^{-1}$, much higher than the 
concentrations usually found in the environment, triggers oxidative stress, evidenced by the inhibition of its growth and morphological damage with disorganization of chloroplasts, lipid damage, increased protein concentration, and increased antioxidant defenses (GSH; superoxide dismutase, SOD and catalase, CAT) (Romero et al., 2011). Choi et al. (2012) found that exposure to GLY affected chlorophyll-a fluorescence in five microalgal species, with certain interspecific differences in GLY sensitivity. Gomes and Juneau (2016), and Gomes et al. (2016a, 2016b) showed a strict relationship between GLY-induced oxidative stress and its deleterious effects on the photosynthetic processes. Also, Eker et al. (2006) and Cakmak et al. (2009) have reported that GLY can bind to different essential metals, causing a decrease in its bioavailability. Duke et al. (2012) have pointed out some contradictions on the mechanism of GLY to bind. The microalga Chlorella vulgaris, is frequently used for analysis of toxicity since it is easily grown under laboratory conditions. This alga is found in many freshwater aquatic environments, and it is seen as a good bioindicator of the presence of environmental contaminants. Qian et al. (2009) and Reno et al. (2016) have reported several studies on effects of the presence of contaminants, such as GLY and its commercial products, on C. vulgaris. More recently, Ostera et al. (2020) reported experimental evidence that strongly suggested that oxidative balance in the hydrophilic cellular environment is affected by GLY independently of the preparation used to administrate the product, even at low-medium concentrations currently in used. Moreover, it seems that the effect is reversible, either due to the magnitude of the herbicide-dependent damage or by the antioxidant activity endogenously activated. However, the reactive oxygen radical (ROS) and nitrogen radical species lead to damage to macromolecules, not only in the hydrophilic but in the hydrophobic medium, as well. The lipid peroxidation is understood as the oxidative deterioration of the polyunsaturated lipids and conduct to effects such as alterations in the structure, fluidity and permeability of cellular membranes. The term lipid radicals $\left(\mathrm{LR}^{\bullet}\right)$, generated by peroxidation, include alkyl, peroxyl ( $\mathrm{ROO}^{\bullet}$ ) and alkoxy radicals. Non-enzymatic lipid soluble antioxidants, such as $\alpha$-Tocopherol $(\alpha-T)$ and $\beta$-Carotene $(\beta-C)$, are aimed to protect, repair, and remove of the radical species generated. The $\mathrm{LR} / \alpha-\mathrm{T}$ ratio was established as an appropriate indicator of oxidative condition in the hydrophobic cellular space (Malanga et al., 2009). Considering the increasing awareness of the environmental risks generated by the use of GLY and its commercial formulations, the cellular pathways that could be affected in non-target organism by the exposure to the herbicide should be further studied. The hypothesis of the present work is that oxidative alterations could affect C. vulgaris redox balance in the hydrophobic cellular medium, consuming lipid soluble antioxidants, after the exposure to either pure GLY or the commercial formulate RUP. The effect of GLY and its formulate was measured on the biomass and rate of growth of the cultures, the oxidation rate of DCFH-DA, the generation rate of $\mathrm{LR}^{\bullet}$, and the content of lipid soluble antioxidants $(\alpha-\mathrm{T}$ and $\beta-C)$.

\section{Materials and Methods}

\section{Culture conditions and experimental design}

Stock axenic cultures of Chlorella vulgaris CPCC90 (Origin: Canadian Phycological Culture Centre, strain identification: C90) were grown in sterilized Bold's Basal medium supplemented with $1 \mathrm{~g} \mathrm{l}^{-1}$ glucose (Bold and Wynne, 1978). Cells were grown at $20 \pm 1^{\circ} \mathrm{C}$ under light/dark cycles of 12:12 h. The irradiance at the surface of the culture was approximately $38 \mathrm{~W} \mathrm{~m}^{-1}$ of photosynthetically active radiation (PAR, Philips 50-W day-light-fluorescent light). Cell abundance was monitored by spectrophotometry $(\lambda=$ $600 \mathrm{~nm}$ ) and cell counting using a hemocytometer. For cell counting, samples were taken and kept in plastic tubes with a solution of formaldehyde in water $10 \%(\mathrm{v} / \mathrm{v})$.

Cells were grown in Bold's Basal medium with $1 \mathrm{~g} \mathrm{l}^{-1}$ of glucose (control cells). For the treatments, the media was supplemented with either analytical grade GLY (SigmaAldrich) or a GLY-based herbicide (RoundUp UltraMax ${ }^{\circledast}$, RUP, donated by colleagues) to a final concentration of active ingredient (GLY) of $0.3 \mu \mathrm{M}$ or $5 \mu \mathrm{M}\left(50 \mu \mathrm{g} \mathrm{l^{-1 }}\right.$ and $800 \mu \mathrm{g} \mathrm{l}^{-1}$, respectively). All determinations were done in exponential (Exp) (day 7) and/or stationary (St) (day 14) growth phases. In each phase the cells were harvested by centrifugation at 9,300 $\mathrm{g}$ at $4^{\circ} \mathrm{C}$. Cells were preserved at $-80^{\circ} \mathrm{C}$ until the time of processing.

The diagram in Fig. 1 shows the experimental protocol designed for these studies.

\section{Oxidation rate of DCFH-DA}

Cellular cultures containing at least $2 \times 106$ cells ml- 1 were used for assaying the oxidation rate of the dye. The harvested cells were resuspended using $400 \mu \mathrm{l}$ of a Tris- $\mathrm{HCl}$ $40 \mathrm{mM}$ pH 7.4 buffer. Two subsamples of this suspension containing $200 \mu \mathrm{l}$ each were taken and transferred to new plastic tubes, then centrifuged at $9,280 \mathrm{~g}$ at $4^{\circ} \mathrm{C}$ for $10 \mathrm{~min}$. The supernatant was discarded and $100 \mu$ l of the same buffer were added to the pellet and resuspended. This new suspension was sonicated for $30 \mathrm{~s}$ using $10 \mathrm{~s}$ continuous pulses. An aliquot of $96 \mu \mathrm{l}$ of buffer and $4 \mu \mathrm{l}$ of DCFH-DA solution in methanol $\left(1 \mathrm{mg} \mathrm{ml}^{-1}\right)$ was added to one of the subsamples. The sample blank was obtained by adding $100 \mu \mathrm{l}$ of buffer to the other subsample. Reactant blank was prepared using the same proportion of buffer:DCFH-DA as the samples and their blanks. Both, the samples and the blanks, were incubated for $45 \mathrm{~min}$ at $30^{\circ} \mathrm{C}$, followed by centrifugation at $9,280 \mathrm{~g}$ for $5 \mathrm{~min}$ at $4^{\circ} \mathrm{C}$. Supernatants were transferred to a 96-wells plaque. Fluorescence was determined at $\lambda \mathrm{ex}=488 \mathrm{~nm}$ and $\lambda \mathrm{em}=525 \mathrm{~nm}$ using a Varioscan Lux microplate reader.

\section{Generation rate of $L R$}

The generation rate of $\mathrm{LR}^{\bullet}$ was determined by electronic paramagnetic resonance (EPR) using a-(4-pyridyl N-oxide)$\mathrm{N}$-tert-butylnitrone $(\mathrm{POBN})$ as a spin trap. Harvested cells were resuspended in $400 \mu \mathrm{l}$ of a $0.5 \mathrm{M} \mathrm{KH}_{2} \mathrm{PO}_{4} / \mathrm{K}_{2} \mathrm{HPO}_{4}$ pH 7.0 buffer and sonicated for 15 s. An aliquot of $200 \mu$ of the resulting homogenate was mixed with an equal volume of a $0.5 \mathrm{M}$ solution of POBN prepared in the same buffer. Samples were placed in a glass micropipette and incubated 


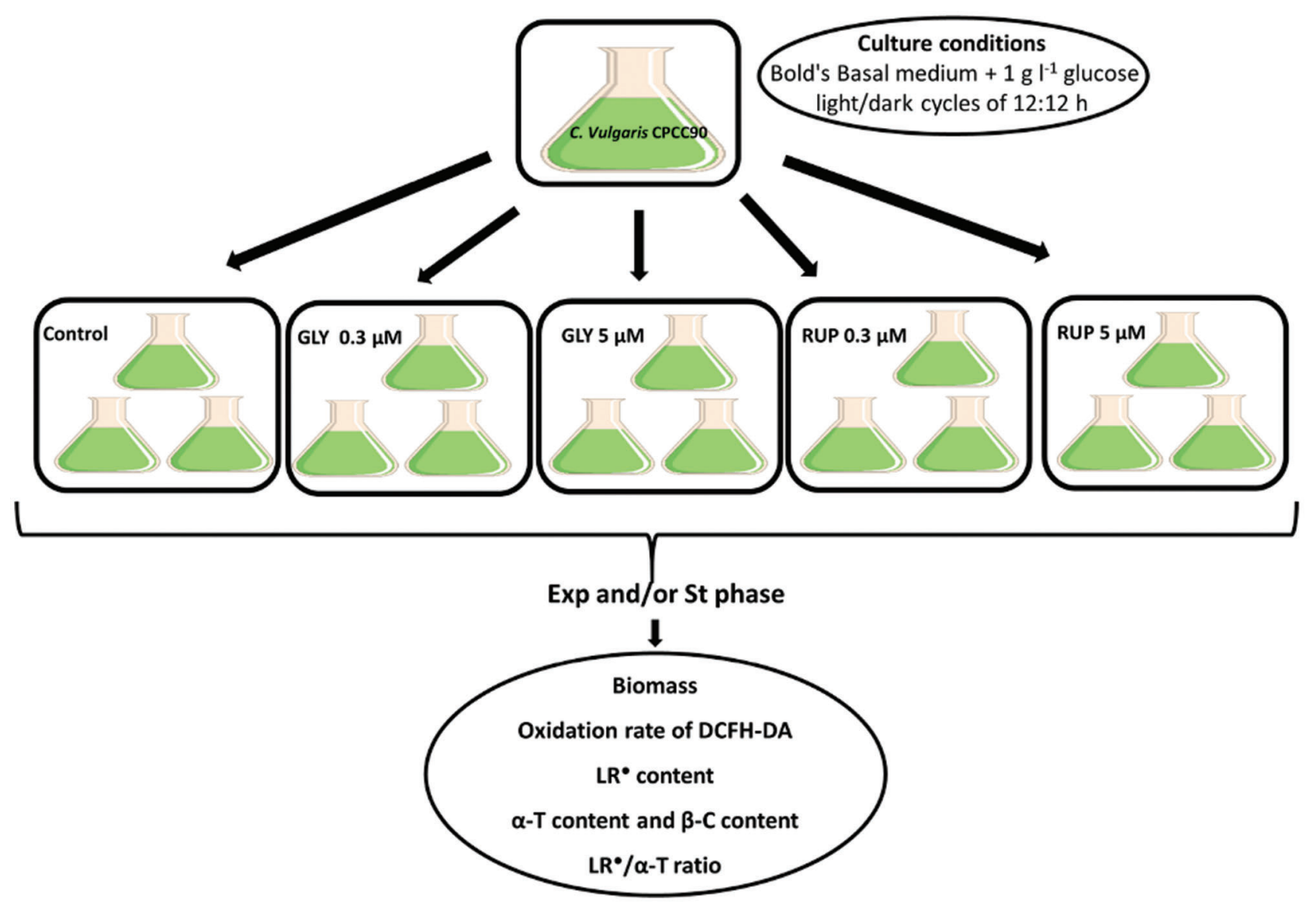

FIGURE 1. Diagram illustrating the experimental design used in this work.

at $30^{\circ} \mathrm{C}$ for $30 \mathrm{~min}$ before $\mathrm{LR}^{\bullet}$ determination. Spectra were measured using a Bruker (Karlsruhe, Germany) spectrometer ECS 106 with a cavity ER 4102ST, operating with the following instrument settings: $18^{\circ} \mathrm{C}$ room temperature, $50 \mathrm{kHz}$ modulation frequency, $20 \mathrm{~mW}$ microwave power, $1 \mathrm{G}$ modulation amplitude, $81.92 \mathrm{~ms}$ time constant and $2 \times$ 104 receiver gain (Buettner and Jurkiewicz, 1993). Quantification of the spin adduct was performed using an aqueous solution of 4-hydroxy-2,2,6,6-tetramethylpiperidinyloxy (TEMPOL) introduced into the same sample cell and subjected to the same treatment as the samples. EPR spectra for both sample and TEMPOL solutions were recorded at exactly the same spectrometer settings and the first derivative EPR spectra were double integrated to obtain the area intensity, from which the content of the radical was calculated according to Kotake et al. (1996).

\section{Content of lipid soluble antioxidants}

The content of $\alpha-\mathrm{T}$ and $\beta-\mathrm{C}$ was determined using high performance liquid chromatography (HPLC) with electrochemical detection in isocratic conditions according to Desai (1984) with modifications. Harvested cells were resuspended in $250 \mu \mathrm{l}$ of a 1:1 methanol:ethanol solution and sonicated for $1 \mathrm{~min}$ for the extraction of the antioxidants. Afterwards, samples were kept for $30 \mathrm{~min}$ in the dark at $4^{\circ} \mathrm{C}$. This procedure was repeated after the addition of $1 \mathrm{ml}$ of hexane. After the last $30 \mathrm{~min}$ of incubation with hexane, samples were centrifuged at 2,320 $\mathrm{g}$ for $10 \mathrm{~min}$ at $4^{\circ} \mathrm{C}$. An aliquot of $750 \mu \mathrm{l}$ of the organic phase was then transferred to a new plastic tube and evaporated to dryness using gaseous $\mathrm{N} 2$ at room temperature. This extract was kept at $-80^{\circ} \mathrm{C}$ until the time of injection. The HPLC procedure was performed using a Perkin-Elmer LC Binary Pump 250, ESA Coulochem II detector, ESA Model 5011 analytical cell, ESA Model 5020 Guard Cell, Perkin Elmer Model 1022 integrator and a manual injector with a $20 \mu \mathrm{l}$ loop. The column employed was a Supelcosil LC-8 (150 mm $\times 4.6 \mathrm{~mm}$; pore size $3 \mu \mathrm{m}$ ). Methanol and a $20 \mathrm{mM}$ solution of lithium perchlorate in distilled water in a 97:3 proportion was used as the mobile phase. Flux was set to $1 \mathrm{ml} \mathrm{min}-1$ for a total run time of 13 to $15 \mathrm{~min}$. Samples were resuspended using $150 \mu \mathrm{l}$ of a 1:1 methanol:ethanol mixture and filtered using Nanosep MF $0.2 \mu \mathrm{m}$ filters previous to injection. Quantification of antioxidants was made by injecting solutions of analytical standards of known concentration.

\section{Statistical analysis}

All statistical analyses were performed using the software GraphPad Prism 6.0. The results are expressed as mean \pm ESM of at least three independent experiments, with three replicates in each experiment and were analyzed using 1-way or 2-way ANOVA with $\mathrm{p}=0.05$ or $\mathrm{p}=0.1$, unless otherwise specified.

\section{Results}

The growth cycle of $C$. vulgaris microalgae comprises three phases: lag phase (days 0-4), Exp phase (days 4-0) and St phase (days 11-14). To evaluate the effects of GLY and 
RUP treatment on the biomass of the cultures, the cell count of the cultures was followed over 14 days, as shown in Fig. 2. A significant $42 \%$ decrease in the cellular biomass in St phase was observed in cultures supplemented with either $5 \mu \mathrm{M}$ of GLY or RUP, as compared to control cultures (Table 1).

Growth rate $(\mu)$ was calculated according to Tajnaiová et al. (2020). The growth rate of cultures exposed to either $5 \mu \mathrm{M}$ of GLY or RUP in Exp phase of development showed a nonsignificant decrease, as compared to control cultures $(0.16 \pm$ $0.04,0.4 \pm 0.1$ and $0.7 \pm 0.2107$ cells $\mathrm{ml}^{-1}$ day $^{-1}$, respectively). Biomass was not affected after exposure of the cells to either $5 \mu \mathrm{M}$ of GLY or RUP in Exp phase of development in agreement with previous reports (Ostera et al. (2020); however, a significant decrease in biomass, evaluated at day 14 in cultures treated with either GLY or RUP, was observed as compared to control cultures (Table 1).

Fig. 3 shows the DCFH-DA oxidation rate in control and GLY - and RUP-treated cultures in Exp and St growth phase. The treatment with $0.3 \mu \mathrm{M}$ of GLY generated nonsignificant effects on the oxidation rate of DCFH-DA, neither in Exp nor in St phase of development as compared to control cultures. However, the treatment with GLY $5 \mu \mathrm{M}$ lead to a significant decrease $(62 \%)$ in the DCFH-DA oxidation rate as compared to control cultures either in Exp and St phase of cellular development, respectively. C. vulgaris cultures showed a significant decrease in the DCFH-DA oxidation rate after supplementation with either

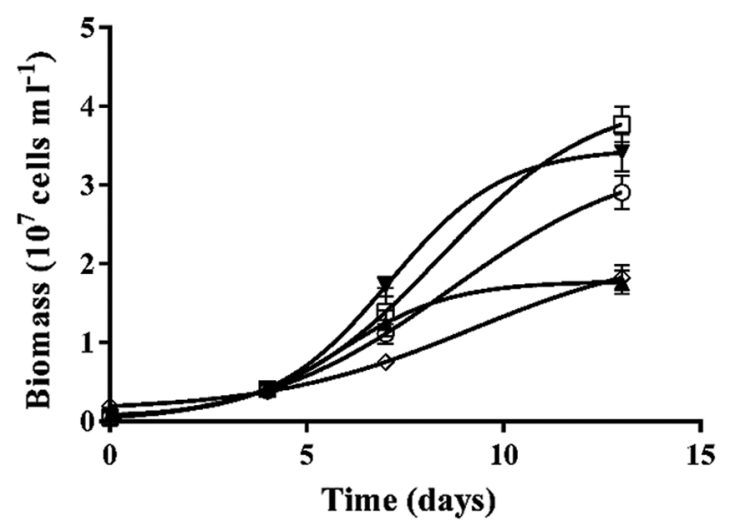

FIGURE 2. Kinetic of the biomass of the cultures of C. vulgaris. Biomass of Control cells $(O)$; and cells grown in the presence of GLY $0.3 \mu \mathrm{M}(\square)$; GLY $5 \mu \mathrm{M}(\diamond)$; RUP $0.3 \mu \mathrm{M}(\boldsymbol{\nabla})$; RUP $5 \mu \mathrm{M}(\boldsymbol{\Delta})$

TABLE 1

Biomass in Exp and St phase of control, GLY- and RUP-treated cultures

\begin{tabular}{lll}
\hline Treatment & \multicolumn{2}{c}{ Biomass $\left(\mathbf{1 0}^{\mathbf{7}}\right.$ cells $\left.\mathbf{~ m}^{\mathbf{- 1}}\right)$} \\
\cline { 2 - 3 } & Exp phase & St phase \\
\hline Control & $1.3 \pm 0.2$ & $3.1 \pm 0.2$ \\
GLY $0.3 \mu \mathrm{M}$ & $1.4 \pm 0.3$ & $3.7 \pm 0.2$ \\
GLY $5 \mu \mathrm{M}$ & $1.1 \pm 0.2$ & $1.8 \pm 0.2^{*}$ \\
RUP $0.3 \mu \mathrm{M}$ & $1.5 \pm 0.2$ & $3.4 \pm 0.2$ \\
RUP $5 \mu \mathrm{M}$ & $1.2 \pm 0.2$ & $1.8 \pm 0.1^{*}$ \\
\hline
\end{tabular}

Note: ${ }^{*}$ significantly different from control cultures (one-way ANOVA, $p<0.05$ ).
$0.3 \mu \mathrm{M}$ or $5 \mu \mathrm{M}$ of RUP in both phases of development. In cultures treated with $0.3 \mu \mathrm{M}$ of RUP a significant $45 \%$ and $56 \%$ decrease in the oxidation rate was observed in Exp and St phase as compared to control cells, respectively. In the presence of $5 \mu \mathrm{M}$ RUP, a significant decrease in the oxidation rate of the dye was observed in Exp and St phase compared to control cultures (52, $47 \%$, respectively).

The LR ${ }^{\bullet}$ generation rate for control and GLY- or RUPtreated cultures is shown in Fig. 4. The $\mathrm{LR}^{\bullet}$ generation rate in Exp growth phase was not significantly affected by the supplementation of cultures with either $0.3 \mu \mathrm{M}$ of GLY or RUP. However, a significant increase $(23 \%)$ in the oxidation rate was observed only in cultures supplemented with $5 \mu \mathrm{M}$ RUP, as compared to control in St phase.

Data in Table 2 shows the content of lipophilic antioxidants, $\alpha-T$ and $\beta-C$, in control, GLY-and RUPtreated cultures in both phases of development. The content of $\beta-C$ was not significantly affected, as compared to control cultures, by any of the treatments in both growth phases of cellular development. In Exp phase, the content of $\alpha$-T was significantly affected by the supplementation with $0.3 \mu \mathrm{M}$ and $5 \mu \mathrm{M}$ of RUP, showing an 87 and $84 \%$ decrease, as compared to control cultures, respectively. In St growth phase supplementation with either 0.3 or $5 \mu \mathrm{M}$ GLY generated a significant 28 and $65 \%$ decrease in the a-T content, as compared to control cultures in the same growth phase, respectively. A significant $92 \%$ decrease was determined in the $\alpha-\mathrm{T}$ content in cultures treated with either 0.3 or $5 \mu \mathrm{M}$ of RUP, as compared to control cultures in this growth phase.

The $\mathrm{LR} / \alpha-\mathrm{T}$ content ratio, considered as an indicator of the balance between free radical damage and antioxidant protection in the hydrophobic medium (Malanga et al., 2009), was significantly different between samples obtained from control and RUP-exposed microalgae in both, Exp and St phase of development at either 0.3 or $5 \mu \mathrm{M}$ formulate (Fig. 5). However, the ratio was not affected when C. vulgaris cells were exposed to $0.3 \mu \mathrm{M}$ GLY in the Exp phase of development (Fig. 5 Insert), showing a more drastic effect of RUP, as compared to GLY tested under the same experimental conditions.

\section{Discussion}

GLY can affect non-target organisms in the aquatic environment, including microalgae and cyanobacteria, which share photosynthetic routes similar to those described for terrestrial plants (Hernández-García and MartínezJerónimo, 2020). They are not only affected in a similar fashion the shikimate pathway, but they also experience oxidative stress as well (Ostera et al., 2016). It was suggested than in addition to producing physiological and metabolic damage that impairs algal growth (Wu et al., 2016), GLY disrupts the integrity of the cell membrane (Amorós et al., 2007). A recent report (Hernández-García and MartínezJerónimo, 2020) evaluated the growth of an experimental community of chlorophycean microalgae (Ankistrodesmus falcatus, C. vulgaris, Pseudokirchneriella subcapitata, and Scenedesmus incrassatulus), by comparing their growth rate in the presence of the herbicide Faena ${ }^{\oplus}$ (1.564 mg GLY/l 


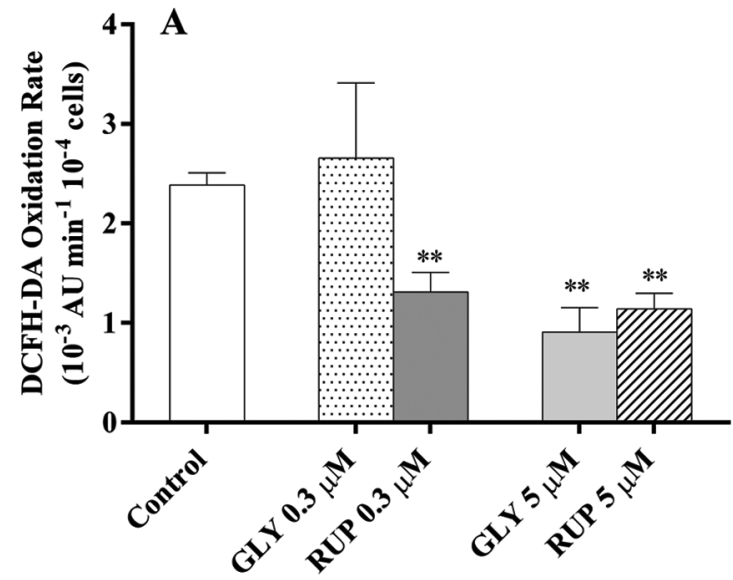

Treatment

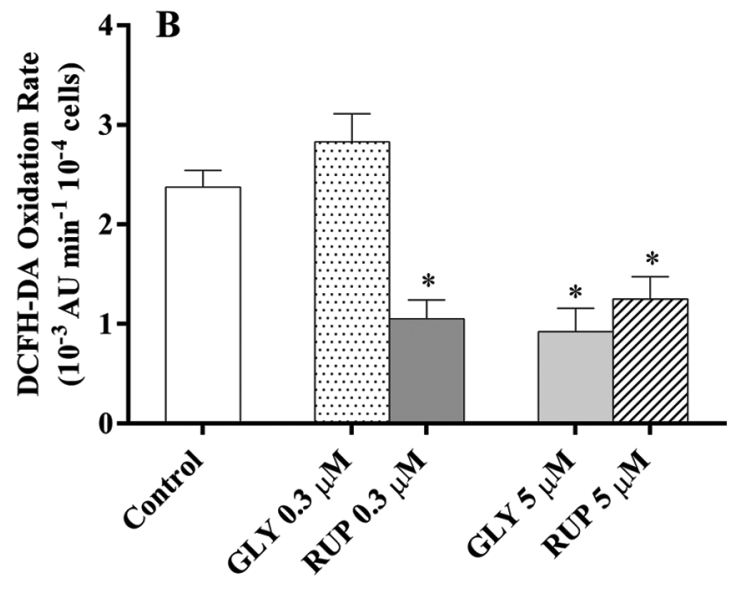

Treatment

FIGURE 3. Oxidation rate of DCFH-DA of the cultures of C. vulgaris in the presence of either GLY or RUP in Exp (A) and St (B) growth phase of development. ${ }^{*}$ significantly different from control cultures in the same growth phase (one-way ANOVA, $p<0.05$. ${ }^{*}$ significantly different from control cultures in the same growth phase (one-way ANOVA, $p<0.1$ ).

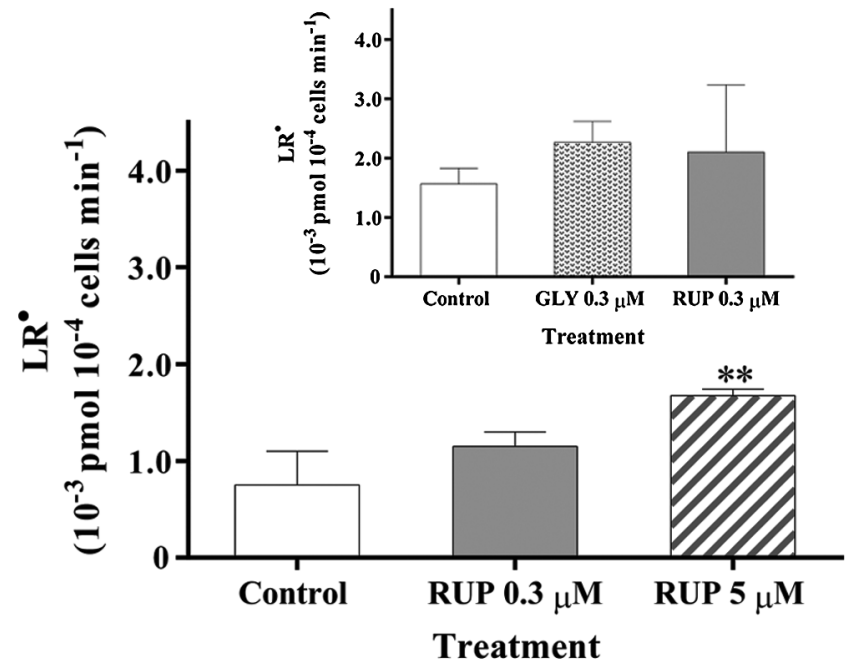

FIGURE 4. LR $^{\bullet}$ generation rate in Control and GLY- RUP-treated cultures in Exp (inset) and St (main figure) growth phase. ${ }^{*}$ significantly different from control cultures in the same growth phase (one-way ANOVA, $p<0.1$ ).

during 14 days for $C$. vulgaris). In that study, negative, significant effects on the growth and physiology of green microalgae (revealed through the assessment of macromolecular and enzymatic biomarkers) were documented. In the same direction, the results reported here employing GLY (either pure or as RUP formulate), in a lower dose than the IC40 used previously, is in agreement with those reports since biomass of the cultures of C. vulgaris was significantly decreased in St phase of development. The observed effect in microalgae may result from the inhibition of the enzyme 5-enolpyruvylshikimate-3phosphate synthase (EPSPS) in the shikimate pathway (Giesy et al., 2000; Pérez et al., 2011) and the possible oxidative stress triggered by the exposure to the herbicide, causing an imbalance in the enzymatic response (Ostera et al., 2016).

The oxidation rate of DCFH-DA was successfully used as a general index of ROS generation in algae exposed to UV-B radiation (Malanga and Puntarulo, 1995), and in soybean roots in vivo exposed to $\mathrm{Fe}$ overload, and as an in vitro assay to study the ability of isolated microsomal membranes
TABLE 2

Content of $\alpha-T$ and $\beta-C$ in control, GLY and RUP-treated cultures in Exp and St growth phase

\begin{tabular}{|c|c|c|}
\hline & $\begin{array}{l}\alpha-T \text { content } \\
\left(\mathrm{pmol} 10^{-4} \text { cells }\right)\end{array}$ & $\begin{array}{l}\beta \text {-C content } \\
\left(\mathrm{pmol} 10^{-4} \text { cells }\right)\end{array}$ \\
\hline \multicolumn{3}{|l|}{ Exp phase } \\
\hline - Control & $0.4 \pm 0.1$ & $0.05 \pm 0.02$ \\
\hline - GLY $0.3 \mu \mathrm{M}$ & $0.3 \pm 0.2$ & $0.04 \pm 0.03$ \\
\hline - GLY $5 \mu \mathrm{M}$ & $0.19 \pm 0.03$ & $0.03 \pm 0.02$ \\
\hline - RUP $0.3 \mu \mathrm{M}$ & $0.05 \pm 0.02^{* *}$ & $0.006 \pm 0.003$ \\
\hline - RUP $5 \mu \mathrm{M}$ & $0.061 \pm 0.004^{*}$ & $0.012 \pm 0.004$ \\
\hline \multicolumn{3}{|l|}{ St phase } \\
\hline - Control & $0.75 \pm 0.07$ & $0.04 \pm 0.02$ \\
\hline - GLY $0.3 \mu \mathrm{M}$ & $0.54 \pm 0.05^{\star *}$ & $0.03 \pm 0.01$ \\
\hline - GLY $5 \mu \mathrm{M}$ & $0.26 \pm 0.08^{*}$ & $0.03 \pm 0.01$ \\
\hline - RUP $0.3 \mu \mathrm{M}$ & $0.06 \pm 0.01^{\star *}$ & $0.005 \pm 0.002$ \\
\hline - RUP $5 \mu \mathrm{M}$ & $0.06 \pm 0.01^{*}$ & $0.005 \pm 0.002$ \\
\hline
\end{tabular}

Note: * significantly different from control cultures in the same growth phase (one-way ANOVA, $p \leq 0.05$ ). ${ }^{*}$ significantly different from control cultures in the same growth phase (one-way ANOVA, $p \leq 0.1$ ).

to generate superoxide anion $\left(\mathrm{O}_{2}^{-}\right)$in the presence of NADPH (Caro and Puntarulo, 1996). Even more, Patetsini et al. (2013) examined, employing flow cytometry, the influence of environmentally relevant concentrations of two pesticides (chlorpyrifos and penoxsulam) on mussel physiological status. These works established this methodology as a reliable biomarker for the evaluation of pollution or other environmental stressors. The data reported here indicated that after the exposure to a low GLY concentration $(0.3 \mu \mathrm{M})$ the oxidation rate of DCFH-DA was not affected neither in Exp nor in St phase of development of C. vulgaris cells. At 


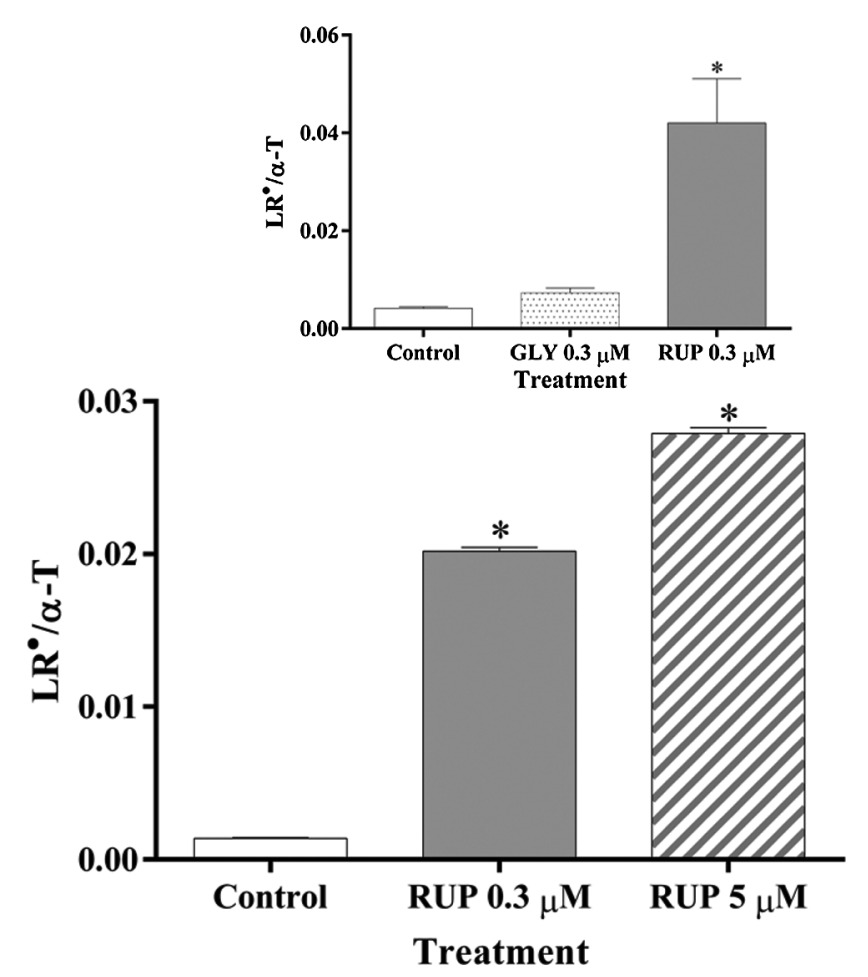

FIGURE 5. LR $\bullet / a-T$ ratio in Control and GLY/RUP treated cultures in Exp (inset) and St (main figure) growth phase. *significantly different from control cultures in the same growth phase (one-way ANOVA, $p<0.05)$.

the highest GLY concentration $(5 \mu \mathrm{M})$ the oxidation rate of the dye was significantly decreased. This decrease was also detected after treatment with RUP at the studied concentrations. This unexpected response could be due to different possible effects of the herbicide:

(a) GLY that could be degraded by processes, such as metal oxides/UV, Fenton/UV, Fenton-like/UV, ozonation, chlorination (Yang et al., 2018) was described to split into PO43- and sarcosine by the chemisorption of $\mathrm{H}_{2} \mathrm{O}$ and ${ }^{-} \mathrm{OH}$ in the existence of Fe oxides (Jaisi et al., 2016). For the sarcosine path, it can react with ${ }^{\bullet} \mathrm{OH}$ and $\mathrm{O}_{2}{ }^{-}$to form glycine and formaldehyde directly. Formaldehyde would be finally oxidized to formic acid and mineralized to $\mathrm{CO}_{2}$ and water. Meanwhile, the decarboxylation of glycine might lead to the formation of methylamine due to the existence of $\bullet^{\bullet} \mathrm{OH}$ (Hidaka et al., 1997). Through the oxidation of $\bullet^{\bullet} \mathrm{OH}$ and $\mathrm{O}_{2}^{-}$, methylamine could be further oxidized to ammonium $\left(\mathrm{NH}_{4}^{+}\right)$, nitrite $\left(\mathrm{NO}_{2}^{-}\right)$and nitrate $\left(\mathrm{NO}_{3}{ }^{-}\right)$ (Manassero et al., 2010). EPR studies verified the existence of ${ }^{\bullet} \mathrm{OH}$ and $\mathrm{O}_{2}{ }^{-}$in both goethite/UV and magnetite/UV systems, and ${ }^{\bullet} \mathrm{OH}$ dominated the photo-degradation of GLY (Yang et al., 2018). In addition, as a highly reactive oxidizing agent, ${ }^{\bullet} \mathrm{OH}$ and $\mathrm{O}_{2}{ }^{-}$could oxidize GLY to amino acid and carboxylic acid, and finally mineralized to inorganic ions. Overall, an effective photo-degradation of GLY in the magnetite/UV system was ascribed to a high capacity of generating ROS, crucially caused by a larger number of dissolved $\mathrm{Fe}$ ions. Fe oxides are the GLY scavengers in soils due to its high affinity with the phosphonate group of GLY (Borggaard and Gimsing, 2008). The sequestration of GLY on Fe oxides has been extensively studied, but the knowledge on the subsequent GLY degradation on $\mathrm{Fe}$ oxides is limited. Due to the extensive existence of goethite and magnetite in nature, it should have a great impact on the fate of pesticides and other organic pollutants in the environment. As ROS can be formed in situ on a mineral surface, it can be reasonably inferred that a similar degradation reaction, described in the environment, will occur in the cells. Thus, the data reported here showing that the amount of reactive ROS available to react with the dye was decreased in the presence of GLY, as compared with the magnitude in its absence, could suggest that similar reactions to those reported in the cellular environment could occur in the cells, and that the presence of $\mathrm{Fe}$ is key factor in this scenario. However, until now this mechanism was not studied in biological organisms and further research in this field is strongly required.

(b) Lipid soluble antioxidants are the best candidates to be involved in the protection mechanisms against GLYdependent damage since oxidative balance in the hydrophilic medium of $\mathrm{C}$ vulgaris cells was affected by this treatment (Ostera et al., 2020). The data reported here clearly suggested that oxidative redox balance was altered at the lipophilic cellular media, such as indicated by the increase in the $\mathrm{LR}^{\bullet}$ generation rate and in the $\mathrm{LR} / \mathrm{a}-\mathrm{T}$ ratio, after exposure of the microalgae to RUP.

The content of $\beta-C$, that is very low in the cell as compared to other antioxidants, did not change by GLY administration. Tocopherol biosynthesis involves two metabolic pathways: the first is via homogentistic acid through the cytosolic shikimate pathway whereas the second is the plastid methylerythritol phosphate pathway for the tocopherol tail (phytyl diphosphate) synthesis. Finally, the assembly of the aromatic ring and phytyl diphosphate tail gives rise to tocopherols (Herrmann and Weaver, 1999). The significant decrease in the content of $\alpha$-T observed in C. vulgaris cells supplemented with either GLY or RUP, strongly suggested that the consumption of this antioxidant is an important defense barrier to the deleterious effect of the herbicide. On the other hand, $a-T$ works synergistically with other antioxidant species such as carotenoids, glutathione (GSH), and ascorbate (AH-) and preserve plastid redox homeostasis in stressed plants (Munné-Bosch, 2005). The formation of these conjugated low molecular weight antioxidants protects further plant metabolism against stress injuries (Szarka et al., 2012). There are two possible means of enhancing conjugated antioxidant formation, increasing either the biosynthesis or the redox cycling of these compounds, and both can result in an increased biological activity of the compounds. In the cell, the interdependence of these antioxidants could play a basic role in electron flow (Gill and Tuteja, 2010).

Synthesis of various aromatic amino acids and precursors of numerous secondary metabolites, like vitamins and pigments takes place through the shikimate pathway (Herrmann and Weaver, 1999). In this pathway, one of the glycolytic cycle compounds, phosphoenol pyruvic acid, and another transitional compound, erythrose-4-phosphate are transformed into chorismate. The reversible synthesis of 5enolpyruvylshikimate 3-phosphate and phosphoenolpyruvate is mediated by the enzyme 5 enolpyruvylshikimate 3 -phosphate synthase (Velisek and Cejpek, 2006) and inhibited by GLY (Lushchak and Semchuk, 2012). Thus, it can be postulated that 
the more drastic decrease in $\alpha$-T content observed in the St phase. as compared to Exp phase, could be due to this inhibitory effect of GLY in the synthesis of the antioxidant required as the growth of the culture proceed.

(c) A contribution of the already mentioned effects (a) and (b) to the decrease of the oxidation rate of the dye in cells exposed to either GLY or RUP.

The abundant and controversial studies on GLY effect on photosynthetic organisms is a clear indication of the complexity of the scenario faced when oxidative metabolism, in both target and non-target plants, is characterized. Further analysis is still required to solve this point. The data presented here are experimental evidence of the contribution of GLY-dependent effects on redox balance in the lipophilic cellular media, that is reflected in the consumption of endogenous antioxidant $\alpha$ $\mathrm{T}$ leading to a potential decrease of the cells ability to afford further oxidative challenges. Moreover, this study shows that the formulate RUP is able to damage the cellular membranes causing deleterious effects on the cells. This is a critical issue for the agrochemical use of the herbicide, since the addition of surfactants is very much used to enhance the efficiency of the product. Thus, characterization of the RUP effects will be encouraged to provide a tool to find new alternatives for its use and, to assess the real contribution of GLY to the reported effects after exposure in the natural environment.

Availability of Data and Materials: All data generated or analyzed during this study are included in this published article (and its supplementary information files).

Author Contribution: GM and SP participated in the designing of the original idea and in the manuscript writing. JMO contributed to experimental work, the bibliographic search and in the manuscript writing. All authors have approved the final article.

Funding Statement: This work was supported by grants from the University of Buenos Aires (UBACyT, 20020170100199BA) and the National Council for Science and Technology (CONICET, PIP 11220170100539CO). SP and GM are career investigators from CONICET.

Conflicts of Interest: GM and SP participated in the designing of the original idea and in the manuscript writing. JMO contributed to experimental work, the bibliographic search and in the manuscript writing. All authors have approved the final article.

\section{References}

Ahsan N, Lee DG, Lee KW, Alam I, Lee SH et al. (2008). Glyphosate-induced oxidative stress in rice leaves revealed by proteomic approach. Plant Physiology and Biochemistry 46: $1062-1070$.

Altamar Ríos J (2007). Factores ambientales de riesgo, radicales libres y enfermedad. Revisión. Revista Electrónica de PortalesMedicos.com. Medicina Preventiva y Salud Pública, 2: 154-155.

Amorós I, Alonso JL, Romaguera S, Carrasco JM (2007). Assessment of toxicity of a glyphosate-based formulation using bacterial systems in lake water. Chemosphere 67: 2221-2228.
Bold HC, Wynne MJ (1978). Cultivation of algae in the laboratory. In: McElroy WD, Swanson CP (eds.), Introduction to the Algae Structure and Reproduction. Englewood Cliffs, NJ: Prentice Hall, 571.

Borggaard OK, Gimsing AL (2008). Fate of glyphosate in soil and the possibility of leaching to ground and surface waters: A review. Pest Management Science 64: 441-456.

Buettner GR, Jurkiewicz BA (1993). Ascorbate free radical as a marker of oxidative stress: An EPR study. Free Radical Biology and Medicine 14: 49-55.

Cakmak I, Yazici A, Tutus Y, Ozturk L (2009). Glyphosate reduced seed and leaf concentrations of calcium, manganese, magnesium, and iron in non-glyphosate resistant soybean. European Journal of Agronomy 31: 114-119.

Caro A, Puntarulo S (1996). Effect of in vivo iron supplementation on oxygen radical production by soybean roots. Biochimica et Biophysica Acta 1291: 245-251.

Chen FX, Zhou CR, Li GP (2012). Study on thermal decomposition and the non-isothermal decomposition kinetics of glyphosate. Journal of Thermal Analysis and Calorimetry 109: 1457-1462.

Choi CJ, Berges JA, Young EB (2012). Rapid effects of diverse toxic water pollutants on chlorophyll a fluorescence: variable responses among freshwater microalgae. Water Research 46: $2615-2626$

Desai ID (1984). Vitamin E analysis methods for animal tissues. Methods in Enzymology 105: 138-147.

Duke SO, Lydon J, Koskinen WC, Moorman TB, Chaney RL, Hammerschmidt R (2012). Glyphosate effects on plant mineral nutrition, crop rhizosphere microbiota, and plant disease in glyphosate-resistant crops. Journal of Agricultural and Food Chemistry 60: 10375-10397.

Eker S, Ozturk L, Yazici A, Erenoglu B, Romheld V et al. (2006). Foliar-applied glyphosate substantially reduced uptake and transport of iron and manganese in sunflower (Helianthus annuus L.) plants. Journal of Agricultural and Food Chemistry 54: 10019-10025.

Giesy JP, Dobson S, Solomon KR (2000). Ecotoxicological risk assessment for Roundup ${ }^{\circ}$ herbicide. Reviews of Environmental Contamination and Toxicology 167: 35-120.

Gill SS, Tuteja N (2010). Reactive oxygen species and antioxidant machinery in abiotic stress tolerance in crop plants. Plant Physiology and Biochemistry 48: 909-930.

Gomes MP, Juneau P (2016). Oxidative stress in duckweed (Lemna minor L.) induced by glyphosate: Is the mitochondrial electron transport chain a target of this herbicide? Environmental Pollution 218: 402-409.

Gomes MP, Le Manac'h SG, Maccario S, Labrecque M, Lucotte M et al. (2016a). Differential effects of glyphosate and aminomethylphosphonic acid (AMPA) on photosynthesis and chlorophyll metabolism in willow plants. Pesticide Biochemistry and Physiology 130: 65-70.

Gomes MP, Le Manac'h SG, Moingt M, Smedbol E, Paquet S et al. (2016b). Impact of phosphate on glyphosate uptake and toxicity in willow. Journal of Hazard Materials 304: 269-279.

Hernández-García CI, Martínez-Jerónimo F (2020). Multistressor negative effects on an experimental phytoplankton community. The case of glyphosate and one toxigenic cyanobacterium on Chlorophycean microalgae. Science of the Total Environment 717: 137-186.

Herrmann KH, Weaver LM (1999). The Shikimate pathway. Annual Review of Plant Physiology and Plant Molecular Biology 50: 473-503. 
Hidaka H, Horikoshi S, Ajisaka J, Zhao J, Serpone N (1997). Fate of amino acids upon exposure to aqueous titania irradiated with UV-A and UV-B radiation Photocatalyzed formation of $\mathrm{NH}_{3}, \mathrm{NO}_{3}^{-}$, and $\mathrm{CO}_{2}$. Journal of Photochemistry and Photobiology A: Chemistry 108: 197-205.

Kotake Y, Tanigawa T, Tanigawa M, Ueno I, Allen DR, Lai C (1996). Continuous monitoring of cellular nitric oxide generation by spin trapping with an irondithiocarbamate complex. Biochimistry and Biophysical Acta 1289: 362-368.

Jaisi DP, Li H, Wallace AF, Paudel P, Sun MJ, Balakrishna A, Lerch RN (2016). Mechanisms of bond cleavage during manganese oxide and UV degradation of glyphosate: results from phosphate oxygen isotopes and molecular simulations. Journal of Agricultural and Food Chemistry 64: $8474-8482$.

Lipok J, Studnik H, Gruyaert S (2010). The toxicity of Roundup ${ }^{\circledR}$ 360 SL formulation and its main constituents: Glyphosate and isopropylamine towards nontarget water photoautotrophs. Ecotoxicology and Environmental Safety 73: 1681-1688.

Lushchak VI, Semchuk NM (2012). Tocopherol biosynthesis: Chemistry, regulation and effects of environmental factors. Acta Physiologiae Plantarum 34: 1607-1628.

Malanga G, Puntarulo S (1995). Oxidative stress and antioxidant content in Chlorella vulgaris after exposure to ultraviolet-B radiation. Physiologia Plantarum 94: 672-679.

Malanga G, Perez A, Calvo J, Puntarulo S (2009). The effect of seasonality on oxidative metabolism in the sea urchin loxechinus albus. Marine Biology 156: 763-770.

Manassero A, Passalia C, Negro AC, Cassano AE, Zalazar CS (2010). Glyphosate degradation in water employing the $\mathrm{H}_{2} \mathrm{O}_{2}$ /UVC process. Water Research 44: 3875-3882.

Munné-Bosch S (2005). The role of $\alpha$-tocopherol in plant stress tolerance. Journal of Plant Physiology 162: 743-748.

Ostera JM, Malanga G, Puntarulo S (2016). Actualización sobre aspectos oxidativos del efecto del glifosato en sistemas biológicos/An update on the effects of glyphosate on the oxidative state in biological systems. Biotecnia 18: 3-10.
Ostera JM, Malanga G, Puntarulo S (2020). Assessment of oxidative balance in hydrophilic cellular environment in Chlorella vulgaris exposed to glyphosate. Chemosphere 248: 125955.

Patetsini E, Dimitriadis VK, Kaloyianni M (2013). Biomarkers in marine mussels, Mytilus galloprovincialis, exposed to environmentally relevant levels of the pesticides, chlorpyrifos and penoxsulam. Aquatic Toxicology 126: 338-345.

Pérez GL, Vera MS, Miranda LA (2011). Effects of herbicide glyphosate and glyphosate-based formulations on aquatic ecosystems. Herbicides and Environment 16: 343-368.

Qian H, Chen W, Sun L, Jin Y, Liu W, Fu Z (2009). Inhibitory effects of paraquat on photosynthesis and the response to oxidative stress in Chlorella vulgaris. Ecotoxicology 18: 537-543.

Reno U, Regaldo L, Vidal E, Mariani M, Zalazar C, Gagneten AM (2016). Water polluted with glyphosate formulations: effectiveness of a decontamination process using Chlorella vulgaris growing as bioindicator. Journal of Applied Phycology 28: 2279-2286.

Romero DM, de Molina MCR, Juarez AB (2011). Oxidative stress induced by a commercial glyphosate formulation in a tolerant strain of Chlorella kessleri. Ecotoxicology and Environmental Safety 74: 741-747.

Szarka A, Tomasskovics B, Bánhegyi G (2012). The ascorbateglutathione- $\alpha$-tocopherol triad in abiotic stress response. International Journal of Molecular Sciences 13: 4458-4483.

Tajnaiová L, Vurm R, Kholomyeva M, Kobera M (2020). Determination of the Ecotoxicity of Herbicides Roundup ${ }^{\circ}$ Classic Pro and Garlon New in aquatic and terrestrial environments. Plants 9: 1203-1224.

Velisek J, Cejpek K (2006). Biosynthesis of food constituents: Amino acids: 2 . The alanine-valine-leucine, serine-cysteine-glycine, and aromatic and heterocyclic amino acids groups. Czech Journal of Food Sciences 24: 45-58.

Wu L, Qiu Z, Zhou Y, Du Y, Liu C, Ye J, Hu X (2016). Physiological effects of the herbicide glyphosate on the cyanobacterium Microcystis aeruginosa. Aquatic Toxicology 178: 72-79.

Yang Y, Deng Q, Yan W, Jing C, Zhang Y (2018). Comparative study of glyphosate removal on goethite and magnetite: Adsorption and photo-degradation. Chemical Engineering Journal 352: 581-589. 